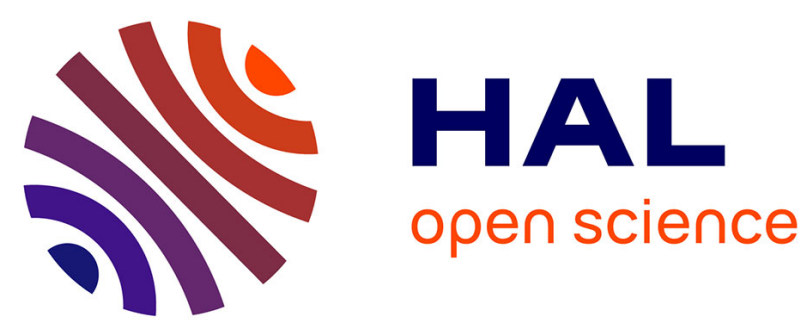

\title{
18th ICPR paper: Cost Performance and Bullwhip Effect in a Hybrid Manufacturing and Remanufacturing System with Different Control Policies
}

Simone Zanoni, Ivan Ferretti, Ou Tang

\section{- To cite this version:}

Simone Zanoni, Ivan Ferretti, Ou Tang. 18th ICPR paper: Cost Performance and Bullwhip Effect in a Hybrid Manufacturing and Remanufacturing System with Different Control Policies. International Journal of Production Research, 2006, 44 (18-19), pp.3847-3862. 10.1080/00207540600857375 . hal00512936

\section{HAL Id: hal-00512936 \\ https://hal.science/hal-00512936}

Submitted on 1 Sep 2010

HAL is a multi-disciplinary open access archive for the deposit and dissemination of scientific research documents, whether they are published or not. The documents may come from teaching and research institutions in France or abroad, or from public or private research centers.
L'archive ouverte pluridisciplinaire HAL, est destinée au dépôt et à la diffusion de documents scientifiques de niveau recherche, publiés ou non, émanant des établissements d'enseignement et de recherche français ou étrangers, des laboratoires publics ou privés. 


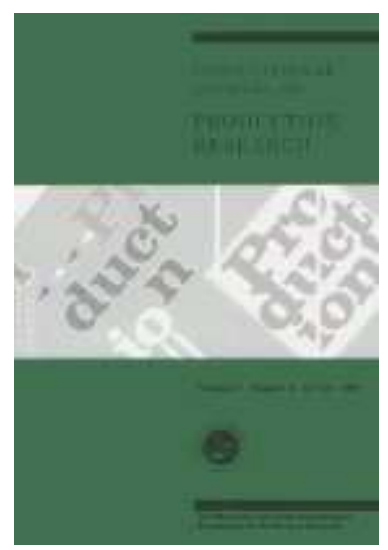

\section{8th ICPR paper: Cost Performance and Bullwhip Effect in a Hybrid Manufacturing and Remanufacturing System with Different Control Policies}

\begin{tabular}{|r|l|}
\hline Journal: & International Journal of Production Research \\
\hline Manuscript ID: & TPRS-2005-IJPR-0522.R2 \\
\hline Manuscript Type: & Original Manuscript \\
\hline Date Submitted by the \\
Author: & 09-Jun-2006 \\
\hline Complete List of Authors: & $\begin{array}{l}\text { Zanoni, Simone; Università di Brescia, Dipartimento di Ingegneria } \\
\text { Meccanica } \\
\text { Ferretti, Ivan; Università di Brescia, Dipartimento di Ingegneria } \\
\text { Meccanica } \\
\text { Tang, Ou; Linköping Institute of Technology, Department of } \\
\text { Production Economics }\end{array}$ \\
\hline Keywords (user): & \begin{tabular}{l} 
REVERSE LOGISTICS, SIMULATION, RE-MANUFACTURING \\
\hline Keywords:
\end{tabular} \\
\hline
\end{tabular}

\section{scholarONE" \\ Manuscript Central}


Cost Performance and Bullwhip Effect in a Hybrid

\title{
Manufacturing and Remanufacturing System with Different
}

\section{Control Policies}

\section{S. ZANONI*†, I. FERRETTI $\dagger$ and O. TANG $\ddagger$}

\begin{abstract}
$†$ Dipartimento di Ingegneria Meccanica, Università degli Studi di Brescia, Via Branze, 38, 25123 Brescia, Italy

$\ddagger$ Department of Production Economics, Linköping Institute of Technology, SE-581 83 Linköping, Sweden
\end{abstract}

*Corresponding author. Email: zanoni@ing.unibs.it 


\title{
Cost Performance and Bullwhip Effect in a Hybrid
}

\section{Manufacturing and Remanufacturing System with Different}

\section{Control Policies}

\begin{abstract}
In recent years, remanufacturing has emerged as an important research area. This requires developing methods and models in order to aid companies in systematically evaluating current as well as projected remanufacturing systems. This paper addresses the inventory control problem in a hybrid inventory system with manufacturing and remanufacturing options. In this study, by changing the definition of inventory position of the serviceable stock, we introduce a shift PULL inventory control policy, which is compared with PULL, DUAL and Separate PULL control policies studied before in literature. Besides evaluating the economic consequences with different control policies, we also study system dynamic behaviour such as the bullwhip effect, in order to understand the advantages and disadvantages of different policies. After the experiments, we propose some management guidelines for such a hybrid inventory system. The major findings are: 1) Separate PULL and DUAL can be good alternatives when manufacturing lead time is significantly larger than remanufacturing one; 2) Shifted PULL exhibits good performance when the two lead times differ slightly. Due to the complexity in solving the optimisation problem, a simulation approach is used.
\end{abstract}

Keywords: Remanufacturing; Reverse Logistics; Closed-loop supply chain; Hybrid inventory systems; Bullwhip effect; Simulation 


\section{INTRODUCTION}

Remanufacturing represents an important form of reuse and focuses on value-added recovery. It has been introduced in many different fields such as automobile, telecommunication, electrical equipment, machinery, etc. In addition to the economic profitability, there is legislation that assigns the producers the responsibility for used products, for instance the Directive 2002/96/EC related to Waste Electrical and Electronic Equipment and the Directive 2002/525/EC related to End of Life Vehicles. Remanufacturing has become an important industrial sector in achieving the goal of sustainable development.

In this paper, we study an inventory system with manufacturing and remanufacturing options. The inventory control policies in this case are often extended from the traditional inventory control models such as $(s, Q)$ and $(s, S)$. The optimal control policy in general is not yet known, except for the case with equal lead times (Kiesmüller, 2003). The most common policies in literature are PUSH and PULL, introduced by van der Laan and Salomon (1997) and then studied by van der Laan et al (1999), Inderfurth and van der Laan (2001), Kiesmüller (2002, 2003), Teunter et al. (2004) among others. These two policies are also widely used in practice.

When the above two policies are implemented, an interesting finding is a so-called lead time paradox, i.e. a short lead time does not necessarily enhance the system performance, especially when the manufacturing and remanufacturing lead times differ considerably (van der Laan et al., 1999, Inderfurth and van der Laan, 2001, Kiesmüller, 2003). This is interpreted as information distortion in the order releasing process. In the standard PUSH and PULL policies, manufacturing orders are trigged by serviceable inventory position, which is defined as on-hand inventory minus backlogs plus outstanding manufacturing and remanufacturing orders. When the lead times differ, this inventory position prevents the possibility of using a fast production model and it does not take into account the potential of overstocking remanufactured items. In order to improve the system 
performance, Inderfurth and van der Laan (2001) modify the policies by postponing remanufacturing orders and reducing the serviceable inventory level, whereas Kiesmüller (2003) and Teunter et al. (2004) examine redefining the inventory position so that better information will be used in making order releasing decisions.

Instead of modifying PUSH and PULL policies, Tang and Grubbström (2005) investigate the benefit of applying a DUAL sourcing policy in the manufacturing and remanufacturing system, i.e. an order is split between two production options. Such an ordering policy reduces inventory holding costs as well as backorder costs when the two lead times are stochastic. In the above study, demand and return rates are considered as deterministic. A preliminary study (Zanoni et al., 2004) shows that DUAL outperforms PUSH and PULL when lead times are significantly different. Thus DUAL policy can complement PUSH and PULL policies in the manufacturing and remanufacturing system.

This background provides the motivation for the current study. We investigate which control policies should be implemented in order to improve the performance in a manufacturing and remanufacturing system with stochastic lead times, stochastic demand and return. Following the same principle as in Kiesmüller (2003), we develop new inventory position definitions for manufacturing and remanufacturing decisions, so that only important inventory and order releasing information is aggregated. Since PULL policy often outperforms PUSH policy (van der Laan et al., 1999), in this study we exclude the latter one.

The impact of system parameters on system performances is investigated in order to understand which policy should be implemented and under what circumstances. In addition to costs, we also consider the bullwhip effect as a performance measure since it is an important indicator of how a sub production system copes with the entire supply chain. Since the system with multiple stochastic 


\section{THE PROBLEM}

\subsection{System description}

We study a hybrid manufacturing and remanufacturing system. The material flows are illustrated in Figure 1. Some items come back to the recoverable inventory after their use by the customer. Customer demand is met by the serviceable stock, which can be replenished by either manufacturing or remanufacturing. These two processes supply the same product, assuming that the remanufactured products are "as good as new", but the lead times often differ. In this study, we further assume that the lead times, demand and return processes are stochastic. A disposal option for return items is not included. As shown in Teunter and Vlachos (2002) such an option generally does not lead to a significant cost reduction. In the system described above, one inventory management issue is to define the inventory control policy at the serviceable stock site: when to order, where to order and how many to order. 


\subsection{PULL and DUAL policies}

According to van der Laan et al. (1999) in a PULL system $\left(s_{m}, Q_{m}, s_{r}, S_{r}\right)$, remanufacturing starts whenever the inventory position of serviceable inventory drops to $s_{r}$ and there is sufficient recoverable inventory to increase the inventory position to $S_{r}$. Manufacturing takes place when the inventory position of serviceable stock drops to $s_{m}$ (Figure 2). The batch size for manufacturing is always $Q_{m}$. Usually the reorder point for manufacturing is not greater than that for remanufacturing $s_{m} \leq s_{r}$ (Figure 2). In this case, the recoverable item is pulled into the process when demand occurs, thus the policy is named PULL. 

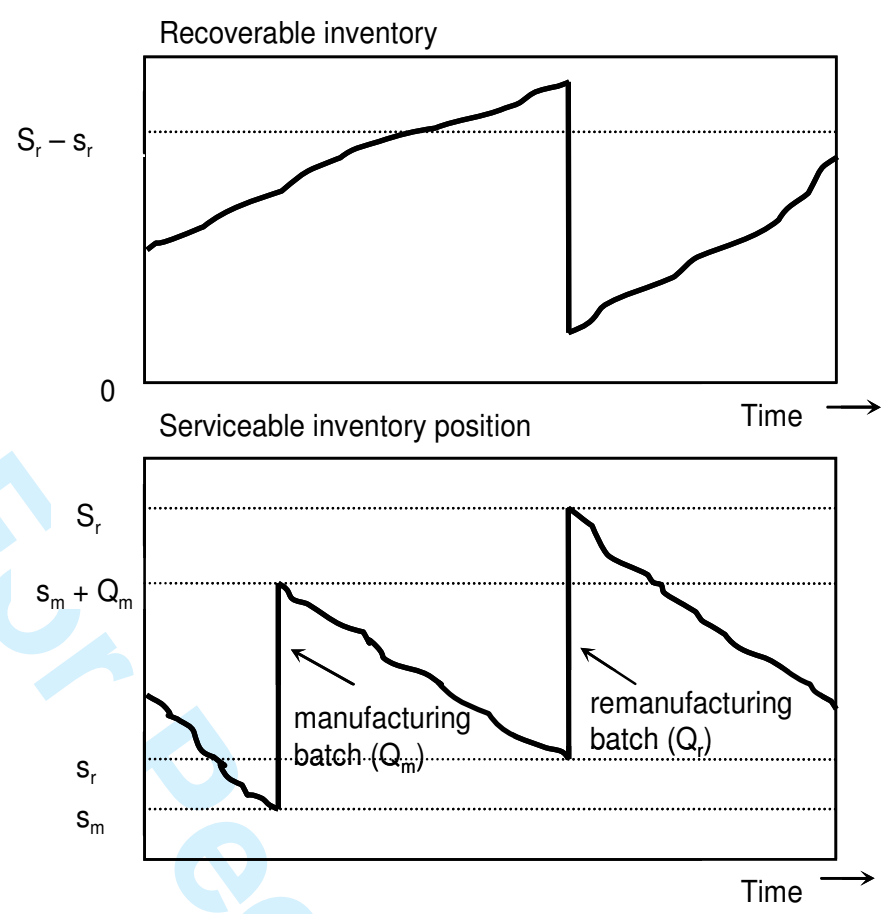

Figure 2. Inventory profile with a PULL policy

The DUAL $(s, Q)$ policy extends the traditional dual sourcing policy (for detail see Tang and Grubbström, 2005). When the inventory position of the serviceable stock drops to or below reorder point $s$, a replenishment order is triggered. This order is split into manufacturing and remanufacturing orders. If the recoverable inventory $Q_{r}$ is less than $Q, Q_{r}$ amount is ordered from remanufacturing process and the rest $\left(Q-Q_{r}\right)$ from manufacturing. Otherwise all $Q$ items are ordered from remanufacturing. The inventory profile in a DUAL system is illustrated in Figure 3. 


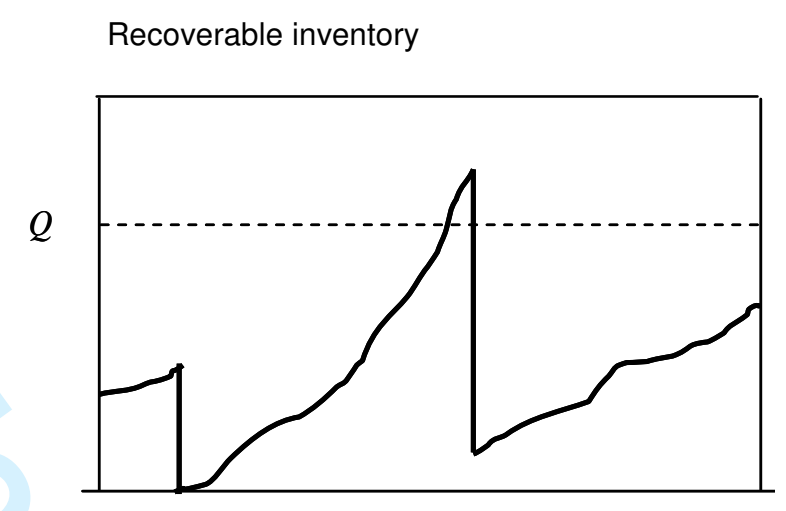

Serviceable inventory position

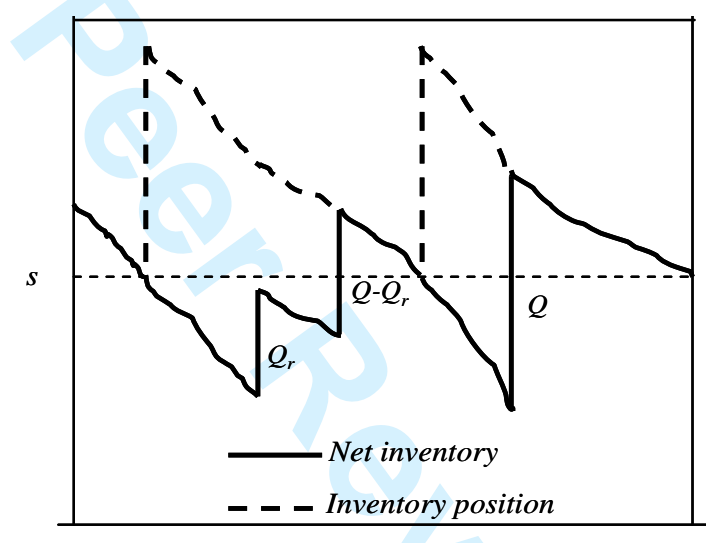

Figure 3. Inventory profile with a DUAL policy

The serviceable inventory position is defined in the same way for the PULL and DUAL policies. It includes the on-hand serviceable inventory minus backorders plus all outstanding manufacturing and remanufacturing orders.

\subsection{Two modified policies}

In the above-mentioned inventory control policies, manufacturing and remanufacturing orders are triggered by examining the inventory position. In the following, the serviceable net-stock (stock-onhand minus backorders) at time $t$ is denoted with $I_{s}(t)$. Furthermore, at decision time point $t$ we have $m\left(t_{1}, t_{2}\right)$ as the outstanding manufactured orders which are released in the time interval $\left[t_{1}, t_{2}\right]$, with $t_{1}<t_{2} \leq t$. Correspondingly, we have outstanding remanufactured orders $r\left(t_{1}, t_{2}\right)$. 
By using this notation, the commonly used inventory position in the literature, defined as the stockon-hand in the serviceable inventory minus backorders plus all outstanding remanufacturing and production orders released before $t$, can be written as:

$$
X(t)=I_{s}(t)+m\left(t-T_{m}, t\right)+r\left(t-T_{r}, t\right)
$$

where $T_{m}$ and $T_{r}$ are respectively the expected manufacturing and remanufacturing lead times in stochastic case.

\subsubsection{Shifted PULL policy}

Now in order to capture the most important inventory and ordering information, we introduce a modified inventory position, considering two additional decision variables which can be optimised. To this end, for the PULL policy we aggregate outstanding orders in two modified inventory positions, which are used for the manufacturing and remanufacturing decisions respectively.

At decision time point $t$ we calculate remanufacturing inventory position as serviceable net-stock, all manufacturing outstanding orders released during time interval $\left[t-T_{m}, t-L_{r}\right]$ and all remanufacturing outstanding orders released during time interval $\left[t-T_{r}, t-L_{r}\right]$. This leads to the following definition

$$
X_{r}(t)=I_{S}(t)+m\left(t-T_{m}, t-\left(T_{m}-L_{r}\right)\right)+r\left(t-T_{r}, t-\left(T_{r}-L_{r}\right)\right)
$$

As illustrated in Figure 4, only the outstanding orders $M_{1}, M_{2}$ and $R_{1}$ will be included in the inventory position. When the manufacturing and remanufacturing lead times are deterministic, these outstanding orders should arrive in the time interval $\left[t, t+L_{r}\right]$. Here $L_{r}$ is a decision variable in our modified replenishment policy and can be optimised via simulation. As this inventory position is lower than the one defined in Equation (1), we retain the chance to trigger a fast production model and therefore reduce the backorders. In a deterministic lead time case, $L_{r}$ should not be larger than $\min \left(T_{m}, T_{r}\right)$ because any time beyond $t+\min \left(T_{m}, T_{r}\right)$ need not be protected due to the availability of 
the fast production model. Since the protection time interval $\left[t, t+L_{r}\right]$ is small, we can also reduce the safety stock level, the reorder point and then the inventory holding cost.

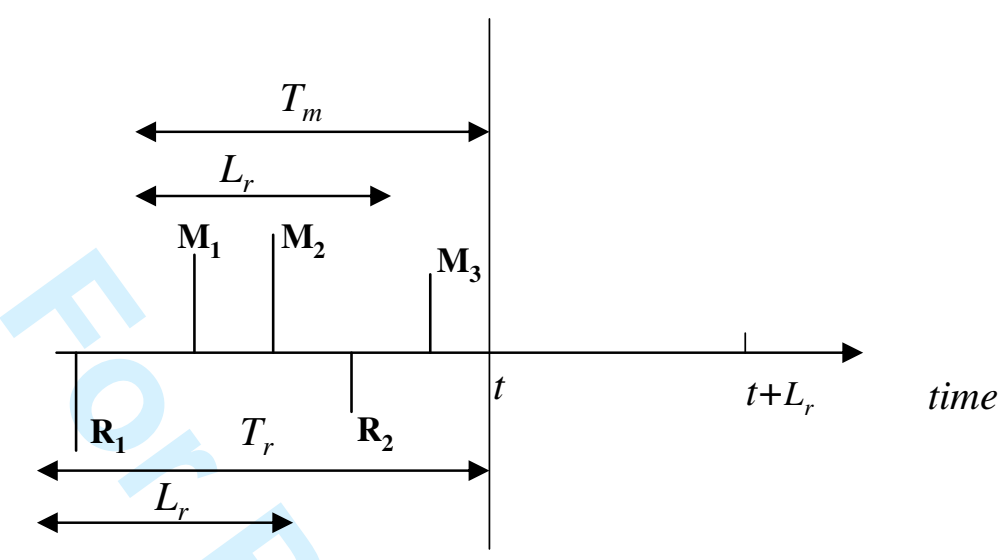

Figure 4. Time scale in defining the new inventory position for the hifted PULL policy

In the same way inventory position for the manufacturing decision is written as

$$
X_{m}(t)=I_{S}(t)+m\left(t-T_{m}, t-\left(T_{m}-L_{m}\right)\right)+r\left(t-T_{r}, t-\left(T_{r}-L_{m}\right)\right)
$$

Since lead times are stochastic in this study, we can not distinguish which actual lead time is larger. Therefore in the above definitions, we do not discriminate between the cases with a large remanufacturing lead time or a large manufacturing lead time. This is also one major difference between our model and the one in Kiesmüller (2003)..

\subsubsection{Separate PULL policy}

With the aim of comparing the performances of the proposed Shifted PULL policy, we also use a modified PULL policy proposed by Teunter et al. (2004), named Separate PULL. The main objective of this policy is to separate as much as possible manufacturing decisions and remanufacturing decisions. The policy is introduced for the special case in which the remanufacturing process is faster than the manufacturing process. In this context the underlying logic is that long-term manufacturing decisions should control the total stock in the system (serviceable inventory position plus remanufacturables), while short-term remanufacturing decisions 


\subsection{System performances}

\subsubsection{System costs}

For both policies described above, we need to evaluate the system performance. The total cost during the planning horizon $T$ is

$$
T C=b \cdot I_{s}^{-}(T)+h_{s} \cdot I_{s}^{+}(T)+h_{r} \cdot I_{r}(T)+K_{m} \cdot M(T)+K_{r} \cdot R(T)
$$

where $b$ is the backorder cost when demand occurs but is not satisfied, $h_{s}$ holding cost for serviceable inventory, $h_{r}$ holding cost for recoverable inventory, $K_{m}$ setup cost when a manufacturing order is released, $K_{r}$ setup cost when a remanufacturing order is released. $I_{S}^{-}(T)$, $I_{S}^{+}(T)$ and $I_{r}(T)$ are backorder, serviceable inventory and recoverable inventory during planning horizon $T$, respectively. $M(T)$ and $R(T)$ are total number of manufacturing and remanufacturing setups.

The marginal costs for manufacturing and remanufacturing are not taken into account. From a long run viewpoint these two costs are constant since the system has a stable return rate and there is no disposal. One should be aware that we need to take extra care when evaluating the inventory 
holding cost rate. Traditionally, we consider inventory holding cost as a capital tied-up due to the cost for obtaining the products. Since in general the marginal manufacturing and remanufacturing costs are different, it becomes more complicated to evaluate how much capital has been tied-up in a serviceable product (Teunter, 2001 and Tang et al. 2004).

\subsubsection{Bullwhip effect}

Besides the total cost, we also evaluate an external performance measure, the bullwhip effect. Since its first theorization (e.g. Forrester, 1961) the bullwhip effect has received much attention as it creates a business environment that can significantly add unnecessary costs (Metters, 1997). To indicate the system dynamics, some authors (e.g. Chen et al., 2000 and Disney et al., 2004) have recently been using the ratio of the long-term variance of orders $(\mathrm{OR})$ over the long-term variance of demand (D) as a measure of the bullwhip effect

Bullwhip index $=\frac{\sigma_{O R}^{2}}{\sigma_{D}^{2}}$

This metric can be applied to a single echelon in a supply or across many echelons in the supply chain (Dejonckheere et al., 2004). With a small value of the bullwhip index, we have a smooth production system (Disney et al., 2004).

Although this study does not consider capacity constraints in the manufacturing and remanufacturing system, it is important examining the bullwhip effect. It determines the extent to which our production process has to re-evaluate resource positioning from one time period to the next and the level at which capacity has to be held to satisfy requirements. In addition, when a manufacturing order is triggered, it often leads to additional material requirements and the information needs to be transferred to the upstream members in a supply chain. Investigation of the bullwhip and variance ratio effects in closed-loop supply chain can also be found in Tang and Naim (2004), Zhou and Disney (2006) and Zhou et al (2006). 
The bullwhip effect index which is taken into account in our study refers to the manufacturing and remanufacturing processes. The bullwhip effect is slightly modified with respect to the one defined above, due to the presence of the return stream

$$
\text { Bullwhip }=\frac{\sigma_{O R}^{2} / \mu_{O R}}{\sigma_{D}^{2} / \mu_{D}}
$$

where $\sigma^{2}$ is the variance and $\mu$ is the mean. The mean values are used to normalise the index. The random external demand is the input to the system, and either the manufacturing order or remanufacturing order is considered as OR. This leads to the following two bullwhip indexes:

$$
\begin{aligned}
& \text { Bullwhip } p_{\text {Manufacturing }}=\frac{\sigma_{\text {Manufacturing orders }}^{2} / \mu_{\text {Manufacturing orders }}}{\sigma_{D}^{2} / \mu_{D}} \\
& \text { Bullwhip } \text { Remanufacturing }_{\text {Remanufacturing orders }} / \mu_{\text {Remanufacturing orders }} \\
& \sigma_{D}^{2} / \mu_{D}
\end{aligned}
$$

\section{SIMULATION MODEL}

The simulation model is coded in Arena ${ }^{\circledR} 8.01$ (by Rockwell Software Inc.) simulation software. Moreover we adopt the optimisation module OptQuest ${ }^{\circledR} 7.0$ (further detail can be found in Kelton et al., 2004) in Arena $^{\circledR}$ to determine the optimal control parameters for the different policies investigated. A range of different scenarios is considered by defining a base case and then varying key parameters. Each scenario is simulated for $T=10,000$ and replicated ten times. The number of replications is sufficient to get a small variance in the simulation results, enabling all the simulations to be included in a 95\% confidence interval. The base case values are given in Table 1. These costs are based on a price of $1000 €$ per finished product. Marginal costs are $200 €$ for each serviceable product and $100 €$ for recoverable product. Inventory holding costs are 
$h_{s}=200 \cdot 0.001=0.2$ and $h_{r}=(200-100) \cdot 0.001=0.1$. We here follow the research results in Teunter (2001) to calculate $h_{r}$ based on the net profit of remanufacturing.

Table 1: Parameters in a base case

\begin{tabular}{|c|c|c|}
\hline Parameter [unit of measure] & Symbol & Value \\
\hline Demand rate [units /period] & $\lambda_{D}$ & 5 \\
\hline Return rate [units /period] & $\lambda_{R}$ & 4 \\
\hline Mean value of remanufacturing lead time [period] & $T_{r}$ & 4 \\
\hline Variance of remanufacturing lead time [period ${ }^{2}$ ] & $\sigma_{T_{r}}^{2}$ & 1 \\
\hline Mean value of manufacturing lead time [period] & $T_{m}$ & 8 \\
\hline Variance of manufacturing lead time [period ${ }^{2}$ ] & $\sigma_{T_{m}}^{2}$ & 1 \\
\hline Backorder cost [€/period/unit] & $b$ & 10 \\
\hline Remanufacturing cost [€/batch] & $K_{r}$ & 2 \\
\hline Manufacturing cost [€/batch] & $K_{m}$ & 5 \\
\hline Holding cost of serviceable inventory [€/period/unit] & $h_{s}$ & 0.2 \\
\hline Holding cost of recoverable inventory [€/period/unit] & $h_{r}$ & 0.1 \\
\hline
\end{tabular}

The uncertainty in our system comes from four different sources: demand process, return process, manufacturing and remanufacturing lead times. In the simulation model, the demand and return in each period follow a Poisson process. In the base case return rate ratio $r\left(r=\lambda_{R} / \lambda_{D}\right)$ is 0.8 . The stochastic lead times for manufacturing and remanufacturing one complete batch obey a Gamma distribution.

\section{RESULTS AND ANALYSIS}

In this section, the optimal decisions for the four control policies are obtained and compared. System performances, in terms of cost and bullwhip effect, are investigated by changing two important parameters. First we vary the mean value of manufacturing lead time and keep the mean value of remanufacturing lead time as a constant. The variances of the two lead times remain 
unchanged. We use five levels of mean lead time ratio $T_{m} / T_{r}=0.5,1,1.5,2,3$. Secondly, we investigate return rate levels from low to high, $r=0.2,0.4,0.6,0.8$.

The simulation results are illustrated in Figures 5 and 6. Optimal control variables are illustrated in Table 2.

\section{Observation 1}

Shifted PULL always generates a better result than PULL policy.

With a Shifted PULL policy, the control variables $L_{m}$ and $L_{r}$ have been optimised. Therefore only "optimal" information (inventory position) has been taken into account in order releasing decisions. This brings better results than PULL, which is the special case whereby $L_{m}=\infty$ and $L_{r}=\infty$. The difference between the two policies is small with high ratio $T_{m} / T_{r}$ (Figure 5). This is interpreted as due to relatively large optimal values of $L_{m}$ and $L_{r}$, and to the fact that most of the outstanding orders have been included in determining the inventory position.

\section{Observation 2}

Separate PULL is the best policy when $T_{m} / T_{r}$ ratio is higher than 1.5.

This result is not surprising as this policy is adapted for a fast remanufacturing system as illustrated in Teunter et al (2004). Our study confirms the advantages of Separate PULL policy.

\section{Observation 3}

The performance of DUAL policy depends both on $T_{m} / T_{r}$ and the return rate level.

From Figure 5, we can see that this policy has a similar behaviour to the Separate PULL policy when the $T_{m} / T_{r}$. ratio is high. With DUAL policy, when the inventory position drops below the reorder point, manufacturing and remanufacturing orders will be released simultaneously. When the manufacturing time is significantly larger than remanufacturing time, the manufacturing order will arrive with a time lag and therefore the inventory holding cost can be reduced. On the other hand, 
the early arrival of the remanufacturing batch reduces the chance of having backorders. The average order sizes of manufacturing and remanufacturing are determined by the return ratio. Ideally, during the time lag between the manufacturing and remanufacturing orders, the first order to arrive should be consumed and the inventory level should drop back again to an appropriate "safety stock" level. In this case both the inventory and backorder reduction effect will be improved. Therefore return ratio should play an important role in determining the performance of DUAL policy.

\section{Observation 4}

Shifted PULL policy is the best policy if $T_{m} / T_{r}<1.5$.

Separate PULL is not suitable for fast manufacturing and DUAL policy does not performe well when the two lead times are close together. Thus Shifted PULL provides the best choice (Figure 6).

\section{Observation 5}

The optimal values for the decision variables $L_{m}$ and $L_{r}$ in Shifted PULL are affected more by the lead time ratio than by the return rate.

This observation follows mainly from the results in Table 2. The principle of Shifted PULL is to use appropriate inventory position information (through adjusting the value of $L_{m}$ and $L_{r}$ ) in order releasing. Since the time period which needs to be protected (from backorders) changes along with the lead time, the optimal reorder point as well as $L_{m}$ and $L_{r}$ should change with the lead time. We also note that with equal lead times, the optimal values of $L_{m}$ and $L_{r}$ are equal in many cases. The second part of the experiment focuses on the bullwhip effect, in both manufacturing and remanufacturing processes. The bullwhip effect indexes in the two processes are reported in Figures 7 and 8.

\section{Observation 6}

DUAL policy usually generates a better result in terms of manufacturing bullwhip. 


\begin{abstract}
Results shown in Figures 7 reveal that the performance of the DUAL policy is usually better than other policies in terms of manufacturing bullwhip effect. In particular the DUAL policy significantly outperforms the other policies when return rate is low. This derives from the fact that in the DUAL policy, unlike the other policies, manufacturing is often needed when an order is released, except where the recoverable inventory $Q_{r}$ is larger than $Q$. However, the situation $Q_{r}>Q$ occurs only when the return rate is high. This implies a more regular release of manufacturing orders.
\end{abstract}

\title{
Observation 7
}

Shifted PULL policy always generates a better result in terms of remanufacturing bullwhip.

Results shown in Figures 8 reveal that the performance of the shifted PULL policy is always better than other policies in terms of remanufacturing bullwhip effect. Shifted PULL shows a relative insensitivity, confirming its outstanding performance in terms of lower remanufacturing bullwhip in the whole set of experiments carried out. With a low return rate (i.e. equal to 0.2 ) different policies exhibit similar values of remanufacturing bullwhip. Whereas with a high return rate (i.e. equal to 0.8) DUAL policy performs worse than other policies. Consistent benefits, in terms of remanufacturing bullwhip, can be observed for intermediate levels of return rate, i.e. in our experiments equal to 0.4 and 0.6 , for each level of lead time ratio. This may be explained as the behaviour of the Shifted PULL policy which releases remanufacturing orders according to a shifted lead time, so as intervals between remanufacturing activities has a reduced level of variability in comparison to the other two PULL policies (i.e. the standard and the Separated). 

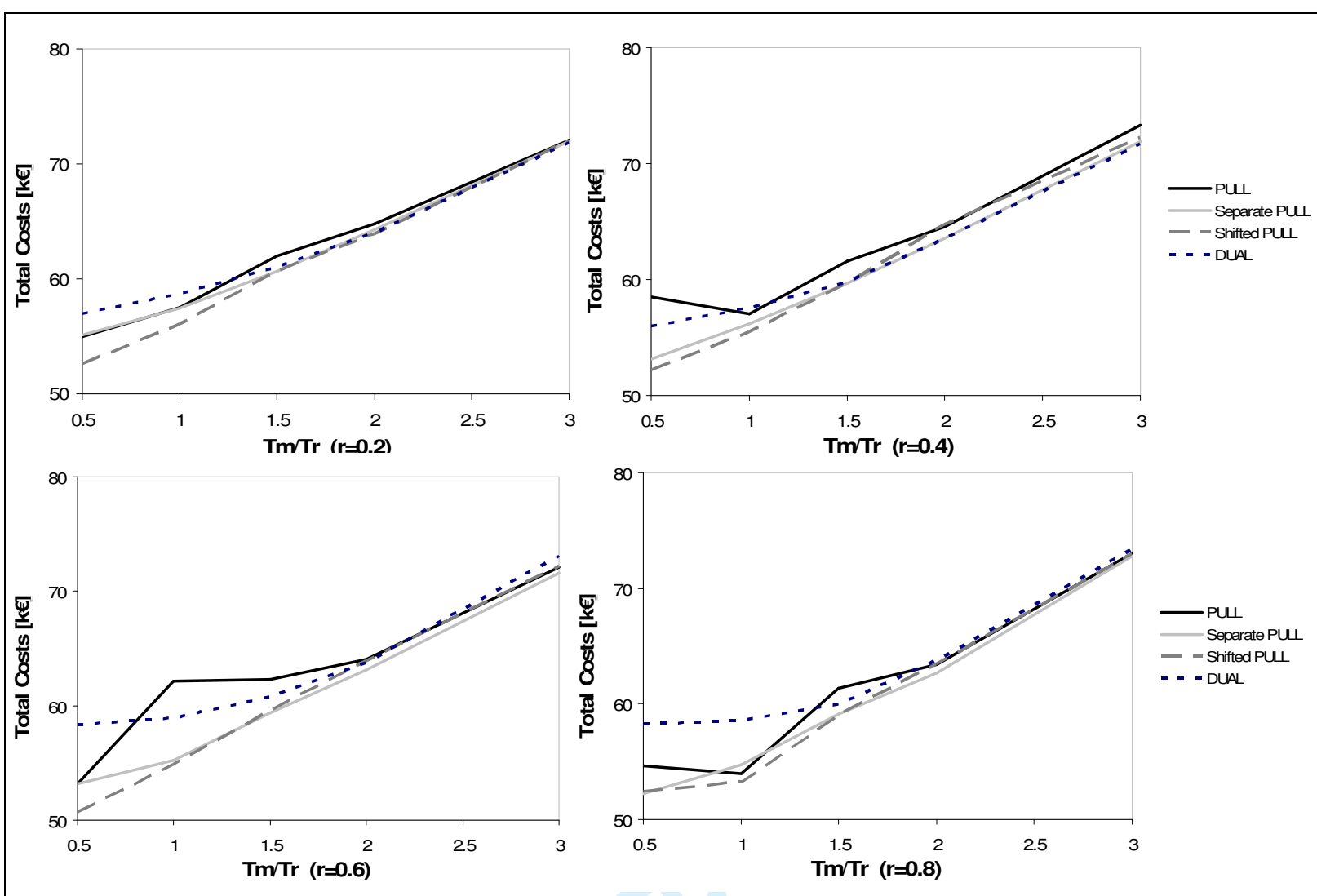

Figure 5. Total costs as a function of mean manufacturing and remanufacturing lead time ratio for four return rate levels 

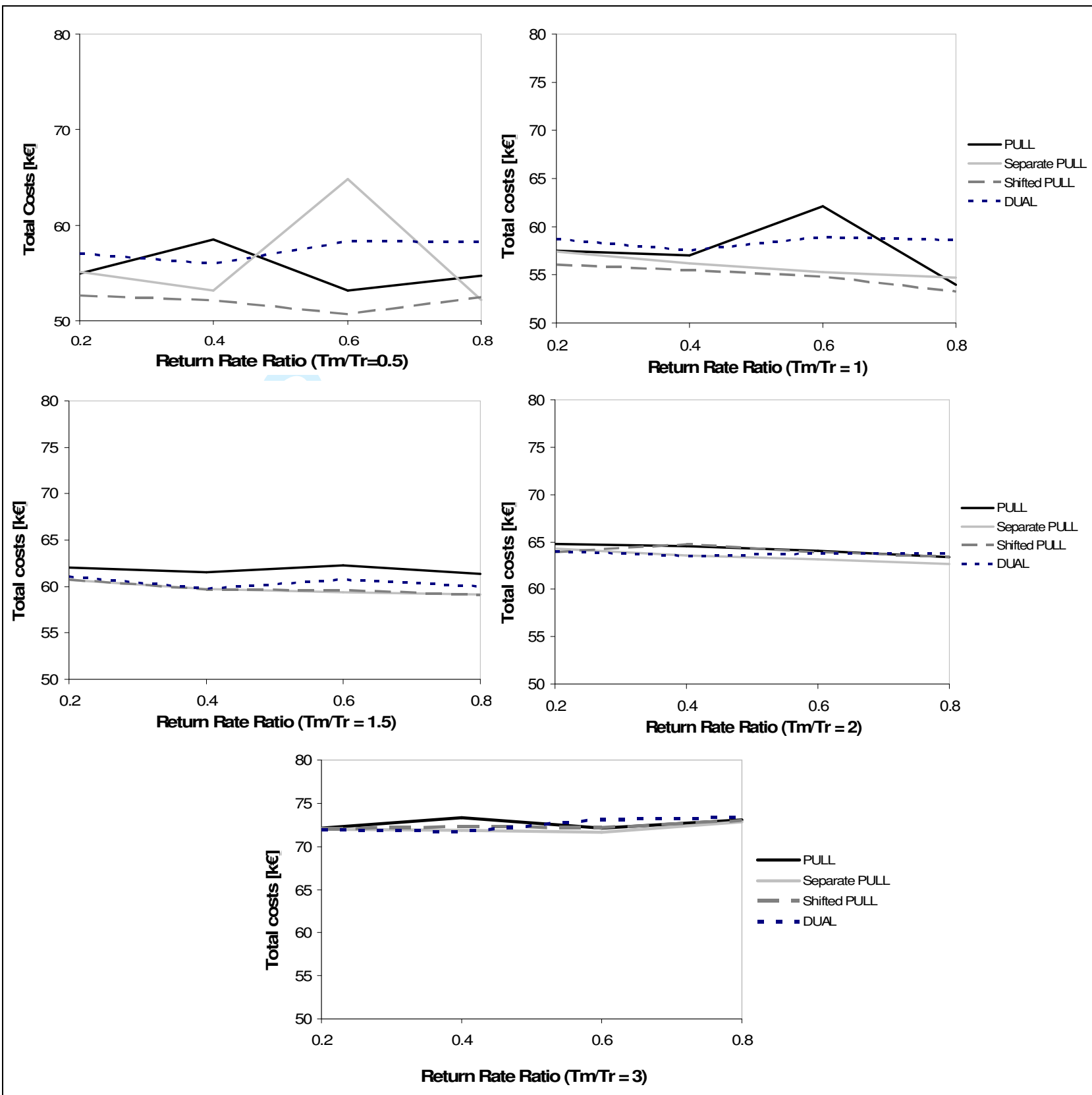

Figure 6. Total costs as a function of return rate for five levels of lead time ratio 
Table2: Values of optimal decision variables for four policies with different scenarios

\begin{tabular}{|c|c|c|c|c|c|c|}
\hline & & \multicolumn{5}{|c|}{$\overline{T_{m} / T_{r}}$} \\
\hline & & 0.5 & 1 & 1.5 & 2 & 3 \\
\hline DUAL $\left(Q, s_{r}\right)$ & \multirow{4}{*}{$r=0.2$} & 17,16 & 21,24 & 22,33 & 23,42 & 21,60 \\
\hline PULL $\left(Q_{m}, Q_{r}, s_{m}, s_{r}\right)$ & & $15,5,17,35$ & $15,6,25,29$ & $21,5,34,47$ & $18,6,44,55$ & $20,6,63,78$ \\
\hline Separate PULL $\left(Q_{m}, Q_{r}, s_{m}, s_{r}\right)$ & & $16,5,19,26$ & $18,5,27,27$ & $14,5,37,37$ & $20,6,45,45$ & $25,5,64,68$ \\
\hline Shifted PULL $\left(Q_{m}, Q_{r}, s_{m}, s_{r}, L_{m}, L_{r}\right)$ & & $16,5,15,26,3,4$ & $17,5,24,30,5,5$ & $14,5,34,34,6,10$ & $18,6,44,56,9,7$ & $20,6,63,78,14,6$ \\
\hline DUAL $\left(Q, s_{r}\right)$ & \multirow{4}{*}{$r=0.4$} & 18,16 & 21,22 & 22,29 & 24,37 & 22,51 \\
\hline PULL $\left(Q_{m}, Q_{r}, s_{m}, s_{r}\right)$ & & $12,10,22,24$ & $14,8,26,32$ & $13,8,35,35$ & $16,7,40,50$ & $21,8,53,69$ \\
\hline Separate PULL $\left(Q_{m}, Q_{r}, s_{m}, s_{r}\right)$ & & $15,7,21,31$ & $15,7,28,28$ & $15,6,35,35$ & $16,8,45,45$ & $14,7,58,62$ \\
\hline Shifted PULL $\left(Q_{m}, Q_{r}, \boldsymbol{s}_{m}, \boldsymbol{S}_{r}, \boldsymbol{L}_{m}, \boldsymbol{L}_{r}\right)$ & & $13,6,17,24,3,5$ & $15,6,24,29,5,5$ & $15,7,32,40,7,15$ & $18,6,38,65,9,8$ & $16,8,55,66,14,18$ \\
\hline DUAL $\left(Q, s_{r}\right)$ & \multirow{4}{*}{$r=0.6$} & 16,20 & 17,24 & 21,27 & 24,31 & 22,43 \\
\hline PULL $\left(Q_{m}, Q_{r}, s_{m}, s_{r}\right)$ & & $13,10,20,27$ & $14,14,28,58$ & $8,9,31,31$ & $13,7,36,46$ & $15,7,47,57$ \\
\hline Separate PULL $\left(Q_{m}, Q_{r}, \boldsymbol{S}_{m}, \boldsymbol{S}_{r}\right)$ & & $15,23,36,36$ & $13,7,28,50$ & $12,8,35,35$ & $13,8,40,40$ & $19,10,51,51$ \\
\hline Shifted PULL $\left(Q_{m}, Q_{r}, \boldsymbol{s}_{m}, \boldsymbol{S}_{r}, \boldsymbol{L}_{m}, \boldsymbol{L}_{r}\right)$ & & $15,8,16,27,3,4$ & $13,7,24,58,5,6$ & $11,8,30,31,6,9$ & $13,7,36,44,10,6$ & $15,7,47,57,16,10$ \\
\hline DUAL $\left(Q, s_{r}\right)$ & \multirow{4}{*}{$r=0.8$} & 12,22 & 13,25 & 15,28 & 14,31 & 16,39 \\
\hline$\overline{P U L L}\left(Q_{m}, Q_{r}, s_{m}, s_{r}\right)$ & & $15,8,15,37$ & $14,8,23,28$ & $15,10,30,33$ & $12,8,33,36$ & $9,8,40,46$ \\
\hline Separate PULL $\left(Q_{m}, Q_{r}, s_{m}, s_{r}\right)$ & & $12,8,24,28$ & $10,8,28,28$ & $9,8,33,35$ & $13,8,35,35$ & $18,8,41,41$ \\
\hline Shifted PULL $\left(Q_{m}, Q_{r}, \boldsymbol{S}_{m}, \boldsymbol{S}_{r}, \boldsymbol{L}_{m}, L_{r}\right)$ & & $14,7,18,37,3,5$ & $10,8,23,28,5,5$ & $12,8,28,31,6,7$ & $12,8,33,36,12,9$ & $9,8,40,46,13,7$ \\
\hline
\end{tabular}




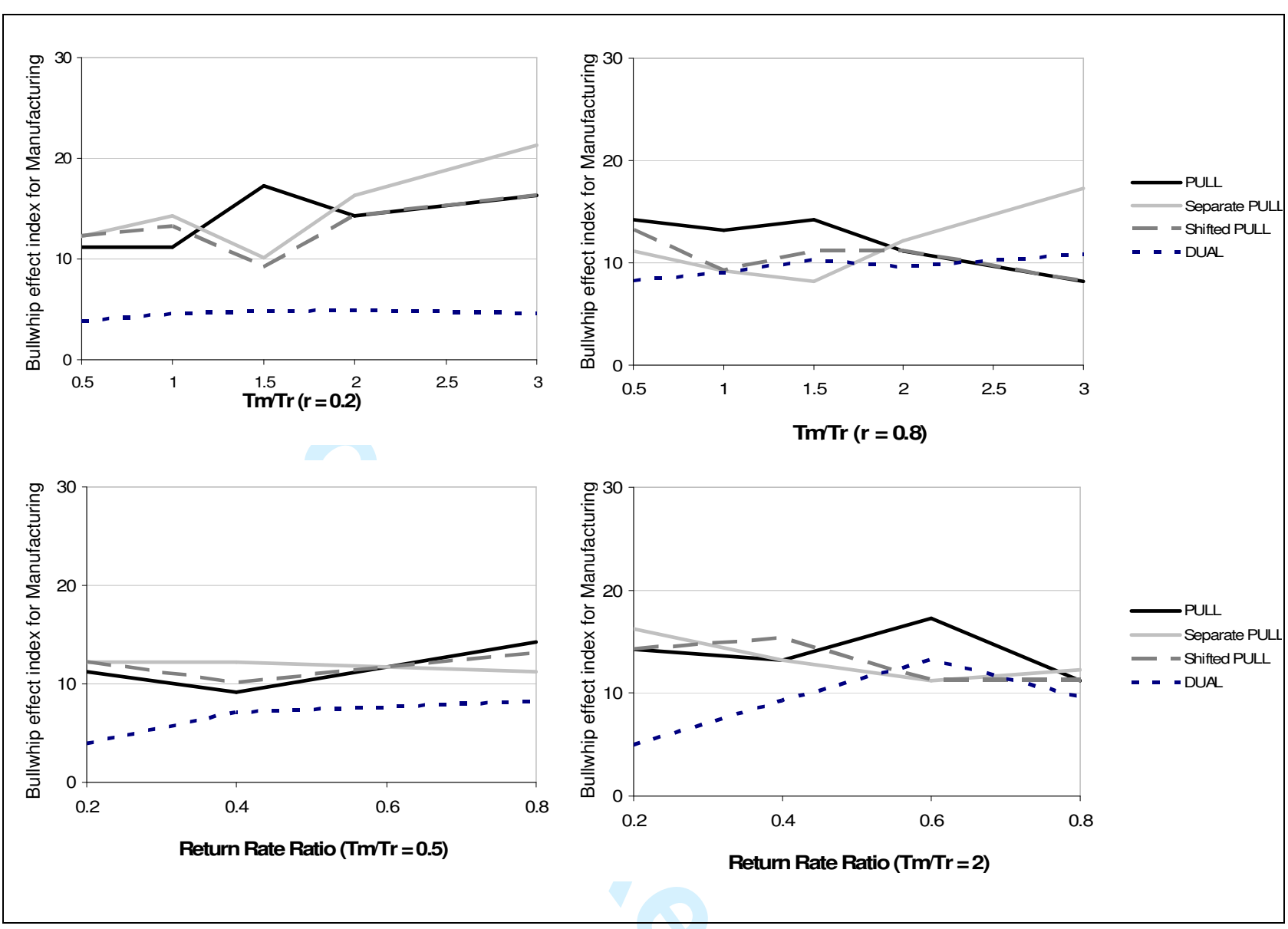

Figure 7. Manufacturing bullwhip effect index for the different policies for four scenarios 

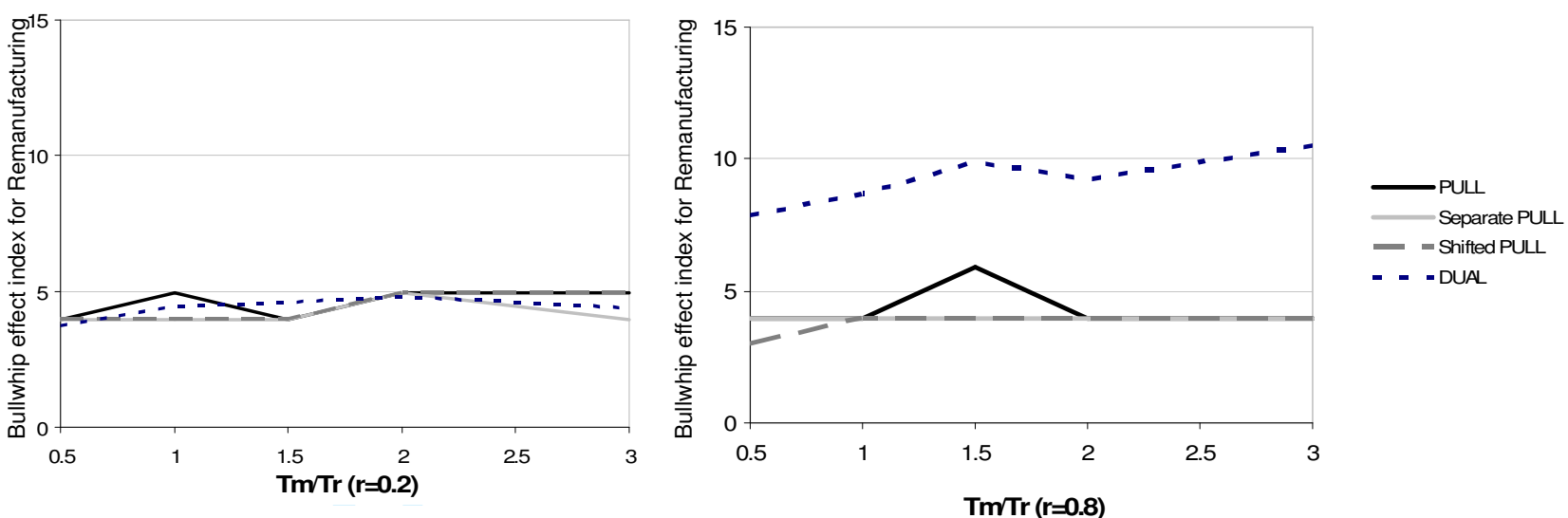
- - Shifted PULL
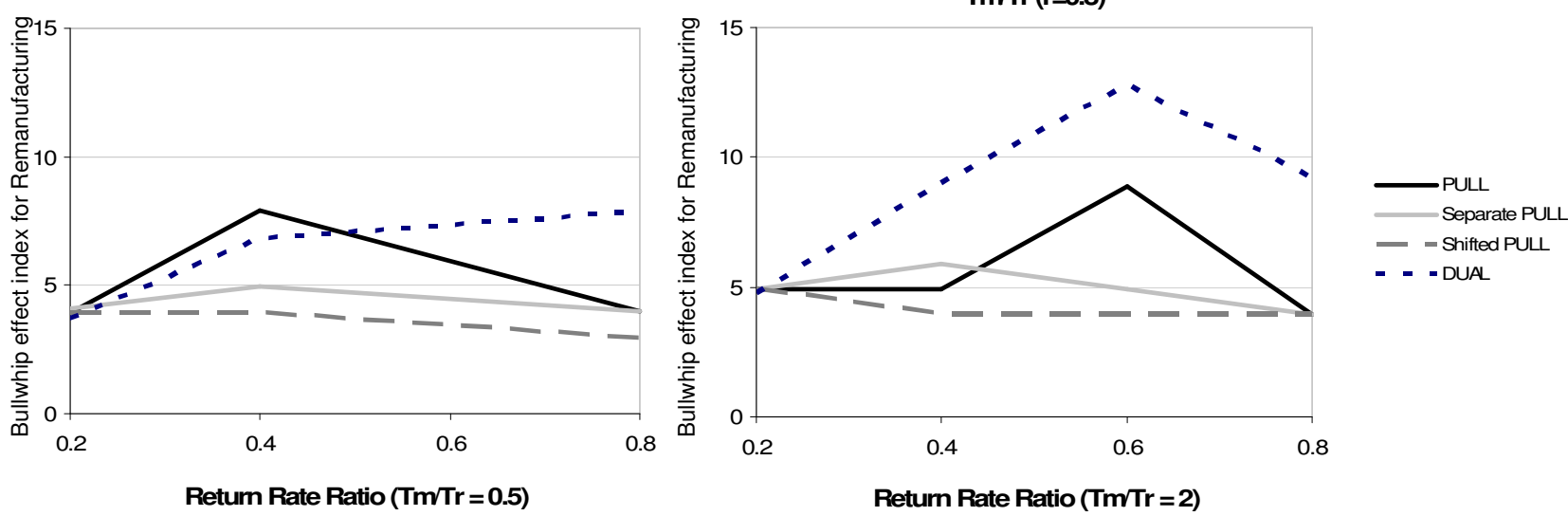
- Shifted PULL - - - DUAL

Figure 8. Remanufacturing bullwhip effect index for the different policies for four scenarios

\section{CONCLUSIONS}

In this paper we have compared different inventory control policies in a hybrid manufacturing/ remanufacturing system where demand, return rate and lead times are stochastic. Standard PULL and Separated PULL policies are used as benchmarks to investigate possible advantages of DUAL policy and newly proposed Shifted PULL policy. In the latter, the manufacturing and remanufacturing decisions are based on two different definitions of the inventory position, which are developed from Kiesmüller (2003).

Through simulation experiments, the Separate PULL policy has been reinvestigated. By comparing the cost performance alone, it has been confirmed that this policy performs very well with respect to the total cost when the remanufacturing lead time is shorter than the manufacturing one (high $T_{m} / T_{r}$ 
ratio), as claimed by Teunter et al. (2004). This policy therefore can be used as a benchmark in a fast remanufacturing system when evaluating other new policies. When the two lead times $T_{m}$ and $T_{r}$ differ slightly, Shifted PULL will be a good choice. The analysis of DUAL policy is more complicated. In order to obtain a good cost performance with DUAL policy, a large lead time difference (either high $T_{m} / T_{r}$ ratio or high $T_{r} / T_{m}$ ratio) is required, and in addition the return ratio should cope with the time difference.

Moreover we calculate the bullwhip effect for different scenarios after the cost has been minimised and the optimal decision variables have been determined. From this aspect, bullwhip effect is used as the supplementary indicator to evaluate system performance associated with different policies in this study. Experiments show that the manufacturing bullwhip effect can be reduced in DUAL policy and the remanufacturing bullwhip can be reduced in Shifted PULL policy. However, it is still hard to find a single policy which provides better results in both processes.

Besides the performance, we should note that there are various difficulties in implementing the above policies. The two control variables in DUAL policy can be readily solved and this policy can be applied in practice relatively easily. Whereas with the Shifted PULL policy, solving the six optimal decision variables can be tedious work and implementing this policy also requires auditing and checking information in several dimensions.

Due to the difficulties in searching for optimal decision variables, this study has to limit the size of the simulation experiment. In order to have an extensive comparison of different policies and confirm the findings in this study, developing heuristics with high solution quality becomes an important direction for future research. Effort should be made to build simple formulae to obtain near-optimal values for the decision variables in the above-mentioned control policies such as Shift PULL, Separated PULL and DUAL. Not till then, can we conduct a more comprehensive study of 
the bullwhip using approaches such as DOE analysis. The results will be of great interest in understanding and managing hybrid production systems.

\section{REFERENCES}

Chen, F., Drezner, Z., Ryan, J.K. and Simchi-Levi, D., Quantifying the bullwhip effect in a simple supply chain: The impact of forecasting, lead-times and information. Management Science, 2000, 46(3), 436-443.

Dejonckheere, J., Disney, S.M., Lambrecht, M.R., Towill, D.R., The impact of information enrichment on the bullwhip effect in supply chains: A control engineering perspective. European Journal of Operational Research, 2004, 152, 727-750.

Disney, S.M., Towill, D.R. and van de Velde, W., Variance amplification and the golden ratio in production and inventory control. International Journal of Production Economics, 2004, 90, 295309

Forrester, J., Industrial Dynamics. MIT Press, 1961, Cambridge, MA.

Inderfurth, K. and van der Laan, E., Leadtime effects and Policy Improvement for Stochastic Inventory Control with Remanufacturing. International Journal of Production Economics, 2001, 71, 381-390.

Kiesmüller, G. P., Control Policies for Recovery Systems with Small Recovery Leadtime, Paper presented at the Twelfth International Symposium on Inventories, Budapest, Hungary, August 19$24,2002$.

Kiesmüller, G. P., A New Approach for Controlling a Hybrid Stochastic Manufacturing/Remanufacturing System with Inventories and different leadtimes. European Journal of Operational Research, 2003, 147, 62-71. 
Kelton, W. D, Sadowski, R.P. and Sturrock, D.T., Simulation with Arena, 3rd Ed., McGraw-Hill, 2004, New York.

Metters, R., Quantifying the bullwhip effect in supply chains. Journal of Operations Management, 1997, 15, 89-100.

Tang, O., Grubbström, R. W. and Zanoni, S., Economic Evaluation of Disassembly Processes in Remanufacturing Systems. International Journal of Production Research, 2004, 42, 3603-3617.

Tang, O. and Grubbström, R. W., Considering Stochastic Lead Times in a Manufacturing/Remanufacturing System. International Journal of Production Economics, 2005, 93-94, 285-300.

Tang, O. and Naim, M. M. (2004), The Impact of Information Transparency on the Dynamic Behaviour of a Hybrid Manufacturing/Remanufacturing System, International Journal of Production Research, 42(19), 4135-4152

Teunter, R. H., A Reverse Logistics Valuation Method for Inventory Control. International Journal of Production Research, 2001, 39(9), 2023-2035.

Teunter, R. H. and Vlachos D., On the necessity of a disposal option for returned products that can be remanufactured. International Journal of Production Economics, 2002, 75, 257-266.

Teunter, R. H., van der Laan, E. and Vlachos, D., Inventory strategies for systems with fast remanufacturing. Journal of the Operational Research Society, 2004, 55, 475-484.

van der Laan, E. and Salomon, M., Production planning and inventory control with remanufacturing and disposal. European Journal of Operational Research, 1997, 102, 264-278.

van der Laan, E., Salomon, M. and Dekker, R., An Investigation of Lead-time Effects in Manufacturing/Remanufacturing Systems under Simple PUSH and PULL control strategies. European Journal of Operational Research, 1999, 115, 195-214. 
Zanoni, S., Tang, O. and Ferretti, I., Comparing Inventory Replenishment Policies in a Reverse Logistics System. Proceeding of 11th Annual International EurOMA Conference, Fontainebleau, France, 27-29 June 2004.

Zhou L. and Disney, S. M., Bullwhip and inventory variance in a closed loop supply chain. $O R$ Spectrum, 2006, 127-149.

Zhou, L., Naim, M. M., Tang, O. and Towill, D. R. (2006), Dynamic Performance of a Hybrid Inventory System with a Kanban Policy in Remanufacturing Process, OMEGA, Vol. 34, Issue 6, pp.585-598 